\title{
Perceived Psychological Well-Being Among University Students: A Comparative Study by Gender
}

\author{
Perla Jannet Jurado García (Dr.) \\ Fernando Mondaca Fernández (M.C.) \\ Leticia Irene Franco Gallegos (M.A.R.H.) \\ Edgar Francisco Ordoñez Bencomo (M.C.) \\ Carolina Jiménez Lira (Dr.) \\ Susana Ivonne Aguirre Vásquez, (Dr.) \\ Autonomous University of Chihuahua, Mexico
}

Doi:10.19044/esj.2019.v15n13p318 URL:http://dx.doi.org/10.19044/esj.2019.v15n13p318

\begin{abstract}
The aim of the present study was to compare the profiles of well-being between men and women Mexican university students. A total sample of 708 participants, 374 women and 334 men, aged 18-26 years participated in this study. A quantitative approach with a descriptive and transversal survey design was used. All the participants completed the Spanish version of the Psychological Well-Being Scales. The results of the one-way multivariate analysis of variance, followed by the one-way univariate analyses of variance, showed that compared with the women, the men obtained higher scores on the subscales self-acceptance, positive relationships, autonomy, environmental mastery, purpose in life and personal growth. Because of the differences between men and women in their perception of well-being found, these findings suggest that in order to design any intervention for improving the perceived well-being of the students, the variable gender should be taken into account.
\end{abstract}

Keywords: Well-being, Student's beliefs; Gender differences; Selfperception

\section{Introduction:}

The question of what is to "feel good" or "live well" can be traced throughout history. For the Greek philosophers "the good life" was a virtue. Aristotle speaks of "the highest good" and the "Sum Happiness" as the goal or purpose of the human life. Also, the disciples of the Chinese philosopher Confucius described a good quality of life in terms of an orderly society where 
every citizen has clearly defined roles and responsibilities and where he/she can exercise them properly (Diener \& Suh, 2000).

Although the interest in the study of well-being has existed for a long time, it is until a few decades that their study has received greater attention, particularly integrated in the field of positive psychology, (Ryff, 2013; Seligman \& Csikszentmihalyi, 2000), and in recent years, empirical and theoretical research on well-being has advanced significantly (Soutter, O'Steen, \& Gilmore, 2014). Furthermore, research on subjective well-being in children has notably increased (Lee \& Yoo, 2015).

In general terms, well-being means to be content, be happy, healthy and prosperous and it refers to an experience of optimal psychological functioning (Deci \& Ryan, 2008). On the other hand, Dodge, Daly, Huyton, \& Sanders (2012) propose a new definition focused on a state of balance, which they name stable well-being. The term stable well-being refers to the availability of psychological, social, and physical resources in order to face a specific challenge (be it psychological, social, or physical); that is, well-being as a balance point between an individual's resources and the challenges he or she is confronted with, concluding that well-being is multi-faceted in nature.

There are two different approaches, but related with most the psychological theories of well-being, they can be classified, one related primarily to happiness (hedonic well-being) and another linked to the development of human potential (eudaimonic well-being) (Delle Fave, Brdar, Freire, Vella-Brodrick, \& Wissing, 2011; Ryan \& Deci, 2001).

The perspective of subjective well-being has shown particular interest in the study of the affections and satisfaction with life, research from the perspective of psychological well-being focuses on skills development and personal growth, conceived both as the main indicators of positive performance, as well as the style and way of dealing with life challenges and the effort and desire to achieve our goals. From this approach, the construct psychological well-being depends less of pleasurable experiences or unpleasurable, but rather in the achievement of the values that make the individual feel alive and authentic and that ultimately allow him to grow and develop as a person (Ryan \& Deci, 2001).

While research in the perspective of psychological well-being or Eudaimonic is related to cognitive function, personality, self-esteem and mood, and includes positive effects, such as vigor, moral and happiness, and negative as, for example, depression and anxiety (Deci \& Ryan, 2008). Psychological well-being has been studied from different aspects; personal and cultural differences that affects it, their predictors and the change of the psychological well-being during life, among others (Diener \& Diener, 1995). In addition, Ryff (2014) states that there is mounting evidence that health 
protection through psychological well-being can reduce the risk of illness and increase the life span.

On the other hand, although it is well known that student's well being is important, there is little agreement as to what this really means; thus, Soutter, O'Steen, \& Gilmore (2014) propose a model around the human development systems to explain the process of well-being among students. The Student Well-being Model (SWBM) includes seven domains: having, being, relating, feeling, thinking, functioning, and to striving. These domains represent specific aspects of students' well-being and can also be used as indicator categories.

Various studies have found a difference in psychological well-being by gender (Barrantes-Brais \& Ureña-Bonilla, 2015; Del Valle, Hormaechea, \& Urquijo, 2015; Rosa-Rodriguez, Negrón, Maldonado, Quiñones, \& Toledo, 2015).

The present research is primarily a descriptive study that attempts to compare the patterns of psychological well-being of men and women Mexican university students; taking into account that in recent years the psychological well-being has taken a huge rise in modern societies.

Consequently, the aims of this research aim, as an applied research, are to: a) provide information that translates into a higher quality educational practice in the context of attention to diversity; and b) contribute to pedagogical knowledge that clarifies the factors that compose a model of integral human development.

\section{Method:}

\section{Participants}

The sample consisted of 708 students of the Faculty of Physical Culture (FCCF) of the Autonomous University of Chihuahua (UACH) Mexico, 374 (52.8\%) women and $334(47.2 \%)$ men.

Age for women ranged between 18 and 26 years, with a mean of 20.26 and a standard deviation of 1.74 years; while age for men fluctuated between 18 and 36 years, with a mean of 20.78 and a standard deviation of 1.95 years.

The sample was obtained by convenience sampling, trying to represent the different semesters of the degrees offered in the FCCF.

\section{Instrument}

The Questionnaire of psychological well-being scales by Ryff, Spanish version adapted by Diaz et al. (2006), consists of 39 items grouped in 6 dimensions or subscales. Internal consistency was acceptable to good for the self-acceptance, $\alpha=.84$, positive relationships, $\alpha=.78$, autonomy, $\alpha=.70$, environmental mastery, $\alpha=.82$, purpose in life, $\alpha=.70$, and personal growth, $\alpha=.71$. 
Self-acceptance is defined by the level at which the individual feels satisfied with his personal attributes. Positive relationships with others underscores the importance of openness and trust in interpersonal relationships; environmental mastery is the ability to choose, create and manage in an opportune manner complicated environments; personal growth is the level at which the person is open to new experiences, which represent challenges which result in achievements; purpose in life refers to setting goals in life, if the person has a sense of direction and specific intentions, the he or she will feel that his or her life has meaning and that there is no problem in it; autonomy refers to the person's ability to regulate his or her own behavior and to be independent.

For our study two adaptations were made:

The first adaptation was to change some terms used in the items of the Spanish version of the questionnaire in order to use a language that would result appropriate in the context of the Mexican culture.

The second adaptation was to apply the instrument through a computer; this was done in order to allow storage of data without prior encoding stages, with greater precision and speed (Figure 1).

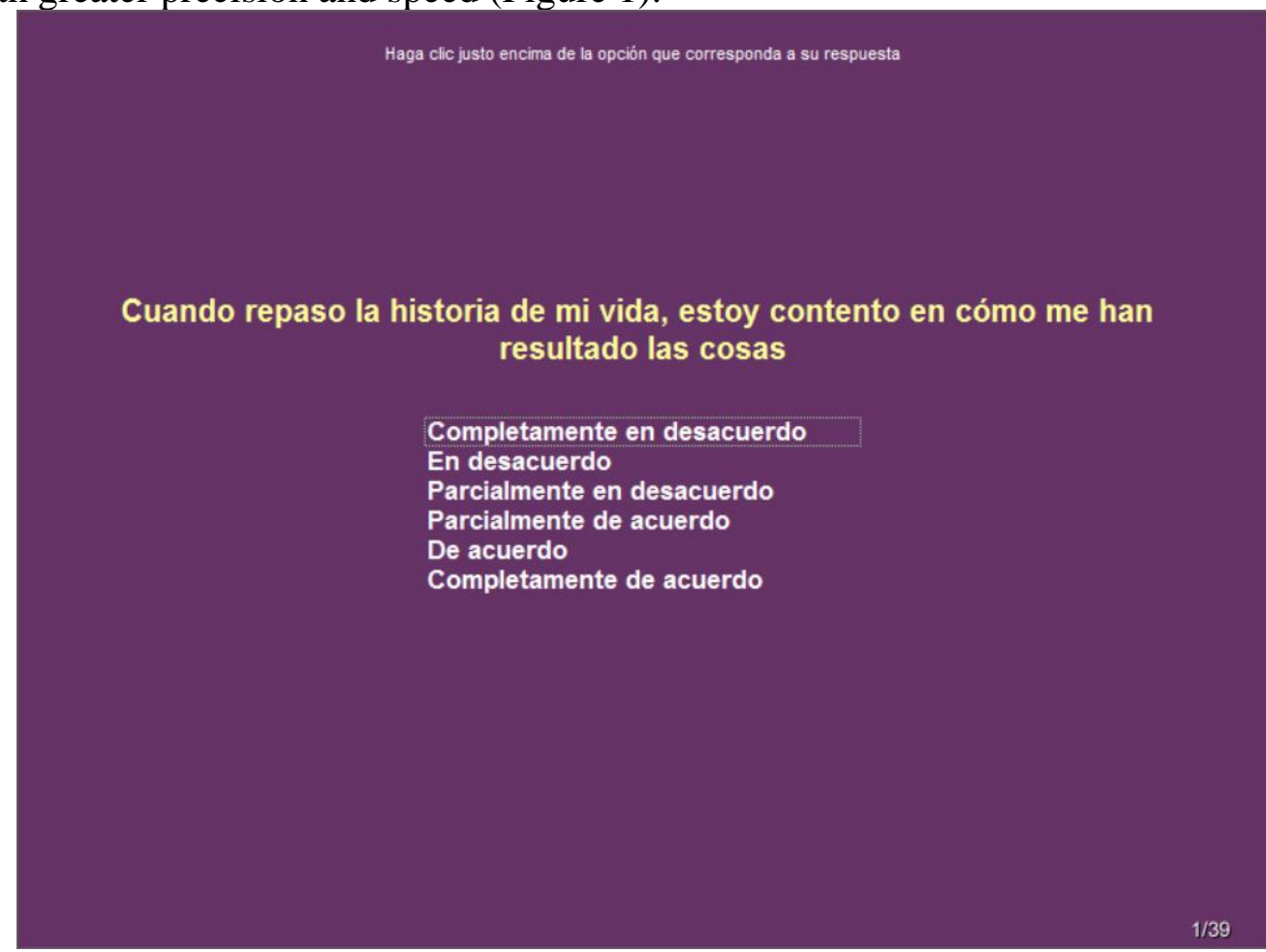

Figure 1 Example of how students responded to the questionnaire item: 
Design

Regarding the design of the study, a quantitative approach with a descriptive and cross-sectional survey design was used (Hernández, Fernández, \& Baptista, 2014). The independent variable was gender (women and men) and the dependent variables were the scores on well-being.

\section{Procedure}

Once the permission of the corresponding educational authorities was obtained, students of the Degrees in Human Motricity and Physical Education of the Autonomous University of Chihuahua (UACH) Mexico, were invited to participate in the study.

Students who agreed to participate signed the letter of informed consent. Then the instrument was applied using a personal computer, in a session that lasted approximately 30 minutes; in the computer labs of the Faculty of Sciences of Physical Culture of the UACH.

At the beginning of the session the researchers gave a general introduction about the importance of the research and how to access the questionnaire through the software. When participants were in the editor, the instructions about how to fill out the questionnaire correctly appeared on screen. Additionally, the participants were advised to ask for help if they were confused about either the instructions or the clarity of a particular item.

At the end of the session students were thanked for their participation.

Once the instrument was applied, data was collected by the results generator module of scales editor, version 2.0 (Blanco et al., 2013).

\section{Data analysis}

Descriptive statistics (means and standard deviations) for all the variables were calculated. Subsequently, after verifying that the data met the assumptions of parametric statistical analyses, a one-way multivariate analysis of variance (MANOVA), followed by the one-way univariate analysis of variance (ANOVA), were used to examine the differences between the men and women on the reported well-being scores. Moreover, the effect size was estimated using the eta-squared $(\eta 2)$. All statistical analyses were performed using the SPSS version 20.0 for Windows (IBM® SPSS $®$ Statistics 20). The statistical significance level was set at $p<.05$.

\section{Results}

Table 1 shows the mean values and standard deviations of well-being for the six factors of the Questionnaire of Psychological Well-being scales of Ryff, Spanish version of Diaz et al. (2006) as well the MANOVA results and subsequents ANOVAs. 
MANOVA results showed statistically significant global differences by gender on the Psychological well-being scores (Wilks $\lambda=.940, \mathrm{p}<.001 ; \eta 2=$ $.060)$.

Subsequently, the ANOVAs indicated that, male students compared with the female students, show higher scores on all subscales of self-acceptance $(F$ $=23.900, p<.001)$, autonomy $(F=16,229, p<.001)$, positive relationships $(F$ $=5.232, p<.05)$, environmental mastery $(F=6.366, p<.05)$ and purpose in life $(F=6.306, p<.05)$; and with no differences in personal growth.

Table 1.Results of MANOVA for the gender differences on the eleven subscales of wellbeing

\begin{tabular}{cccrcr}
\hline & $\begin{array}{c}\text { women } \\
(n=374)\end{array}$ & $\begin{array}{c}\text { men } \\
(n=334)\end{array}$ & \multicolumn{1}{c}{$F$} & \multicolumn{1}{c}{$p$} & \multicolumn{1}{c}{$\eta^{2}$} \\
\hline & & & 7.414 & $<.001$ & .060 \\
Self-acceptance & $3.54(0.04)$ & $3.82(0.04)$ & 23.900 & $<.001$ & .033 \\
Autonomy & $3.01(0.04)$ & $3.24(0.04)$ & 16.229 & $<.001$ & .022 \\
Positive relationships & $3.57(0.04)$ & $3.71(0.05)$ & 5.232 & $<.05$ & .007 \\
Environmental mastery & $3.74(0.03)$ & $3.86(0.05)$ & 6.366 & $<.05$ & .009 \\
Purpose in life & $3.84(0.04)$ & $3.98(0.04)$ & 6.306 & $<.05$ & .009 \\
Personal growth & $3.87(0.03)$ & $3.81(0.03)$ & 1.449 & $>.05$ & \\
\hline
\end{tabular}

Note. Descriptive values are reported as mean (standard deviation).

\section{Discussion}

The obtained results show that in five of the areas or factors of psychological well-being, men perceived themselves better than women; it can be concluded that women show less psychological well-being; conclusion that, in general, is consistent with similar studies (Barrantes-Brais \& UreñaBonilla, 2015; Del Valle, Hormaechea, \& Urquijo, 2015; García-Alandete, 2013; Rosa-Rodríguez, Negrón, Maldonado, Quiñones, \& Toledo, 2015) where there are also reports that women tend to have lower levels of psychological well-being than men; that is, they feel dissatisfied with themselves; more distrustful of interpersonal relationships; they are more influenced by the opinions of others and by the social pressure regarding how to think and act; they feel more unable to change or improve the environment and they have more difficulty finding meaning in life; in contrast to Lindfors, Berntsson, \& Lundberg (2006) who report higher scores on all dimensions of psychological well-being except on environmental mastery.

These results can be explained on the basis that, for reasons of gender stereotypes of the Western culture, men have more development opportunities and thereby improve their perception of psychological well-being to a greater extent than women. That is, the process of socialization to encourage certain ways of thinking, feeling and acting depending on whether it is male or female, promotes gender identity; which explains the development of different beliefs between men and women (Rosa-Rodríguez et al, 2015). 


\section{Conclusion:}

The differences found between men and women regarding their psychological well-being, also suggest, that when designing any kind of intervention that aims to improve it, gender should be taken into account. The importance of conducting more research on the subject in our country is also emphasized; as stated by Weiss, Westerhof \& Bohlmeijer (2016) it is possible to improve psychological well-being with behavioral interventions that allow a person a better development.

At least two limitations are present in this work. The first is that participants are only Mexican university students, which threatens the possibility of generalizing these results. Expanding the sample (for example adding young adults who are not students) is a work area for the future. The second limitation comes from the measuring instrument itself, which is based on self-inform and therefore may contain biases that result from social desirability.

\section{Acknowledgements}

This study is part of a project funded by the Secretaría de Educación Pública-Subsecretaría de Educación Superior-Dirección General de Educación Superior Universitaria de México [Mexican Ministry of EducationDepartment of Higher Education-General Directorate of the University Education] (OF-13-6894).

\section{References:}

1. Barrantes-Brais, K., \& Ureña-Bonilla, P. (2015). Bienestar psicológico y bienestar subjetivo en estudiantes universitarios costarricenses. Revista Intercontinental de Psicología y Educación, 17(1).

2. Blanco, H., Ornelas, M., Tristán, J. L., Cocca, A., Mayorga-Vega, D., López-Walle, J., \& Viciana, J. (2013). Editor for creating and applying computerise surveys. Procedia Social and Behavioral Sciences, 106, 935-940. doi:http://dx.doi.org/10.1016/j.sbspro.2013.12.105

3. Deci, E. L., \& Ryan, R. M. (2008). Hedonia, Eudaimonia, and WellBeing: an Introduction. Journal of Happiness Studies, 9(1), 1-11. doi:10.1007/s10902-006-9018-1

4. Delle Fave, A., Brdar, I., Freire, T., Vella-Brodrick, D., \& Wissing, M. P. (2011). The Eudaimonic and Hedonic Components of Happiness: Qualitative and Quantitative Findings. Indicators Research, 100(2), 185-207. doi:10.1007/s11205-010-9632-5

5. Del Valle, M. V., Hormaechea, F., \& Urquijo, S. (2015). El bienestar psicológico: diferencias según sexo en estudiantes universitarios y diferencias con población general. Revista Argentina de Ciencias del Comportamiento, 7(3). 
6. Díaz, D., Rodríguez-Carvajal, R., Blanco, A., Moreno-Jiménez, B., Gallardo, I., Valle, C., \& van Dierendonck, D. (2006). Adaptación española de las escalas de bienestar psicológico de Ryff. Psicothema, 18(3), 572-577.

7. Diener, E., \& Diener, M. (1995). Cross-cultural Correlates of Life Satisfaction and Self-esteem. Journal of Personality and Social Psychology, 68(4), 653-663.

8. Diener, E., \& Suh, E. M. (2000). Culture and Subjective Well-being. Cambridge, Massachusetts: MIT Press.

9. Dodge, R., Daly, A. P., Huyton, J., \& Sanders, L. D. (2012). The challenge of defining wellbeing. International journal of wellbeing, 2(3), 222-235.

10. García-Alandete, J. (2013). Bienestar psicológico, edad y género en universitarios españoles. Salud y Sociedad: Investigaciones en psicología de la salud y psicología social, 4(1), 48-58.

11. Hernández, R., Fernández, C., \& Baptista, P. (2014). Metodología de la investigación. México: McGraw- Hill.

12. Lee, B. J., \& Yoo, M. S. (2015). Family, school, and community correlates of children's subjective well-being: An international comparative study. Child Indicators Research, 8(1), 151-175. doi: 10.1007/s12187-014-9285-z

13. Lindforsa, P., Berntssonc, L., \& Lundberg, U. (2006). Factor structure of Ryff's psychological well-being scales in Swedish female and male white-collar workers. Personality and Individual Differences, 40(6), 1213-1222. doi:10.1016/j.paid.2005.10.016

14. Soutter, A. K., O'Steen, B., \& Gilmore, A. (2014). The student wellbeing model: A conceptual framework for the development of student well-being indicators. International Journal of Adolescence and Youth, 19(4), 496-520. doi: 10.1080/02673843.2012.754362

15. Rosa-Rodríguez, Y., Negrón, N., Maldonado, Y., Quiñones, A., \& Toledo, N. (2015). Dimensiones de bienestar psicológico y apoyo social percibido con relación al sexo y nivel de estudio en universitarios. Avances en Psicología Latinoamericana, 33(1), 31-43. doi:10.12804/apl33.01.2015.03

16. Ryan, R. M., \& Deci, E. L. (2001). On happiness and human potentials: A review of research on hedonic and eudaimonic well-being. Annual Review of Psychology, 52, 141-166.

17. Ryff, C. D. (2013). Eudaimonic well-being and health: Mapping consequences of self-realization. In A. S. Waterman (Ed.), The best within us: Positive psychology perspectives on eudaimonia (pp. 7798). Washington, DC: American Psychological Association. 
18. Ryff, C. D. (2014). Psychological well-being revisited: Advances in the science and practice of eudaimonia. Psychotherapy and psychosomatics, 83(1), 10-28. doi: 10.1159/000353263

19. Seligman, M. E. P., \& Csikszentmihalyi, M. (2000). Positive Psychology: An introduction. American Psychologist, 55(1), 5-14.

20. Soutter, A. K., O'Steen, B., \& Gilmore, A. (2014). The student wellbeing model: A conceptual framework for the development of student well-being indicators. International Journal of Adolescence and Youth, 19(4), 496-520. doi: 10.1080/02673843.2012.754362

21. Weiss, L. A., Westerhof, G. J., \& Bohlmeijer, E. T. (2016). Can we increase psychological well-being? The effects of interventions on psychological well-being: a meta-analysis of randomized controlled trials. PloS one, 11(6), 1-16. doi: 10.1371/journal.pone.0158092 